\title{
Inversiones y solución de controversias: el proyecto dentro de la Unasur y propuestas alternativas
}

\section{Investment and Dispute Settlement: the Project within the Unasur and Alternative Proposals}

\section{Javier Echaide*}

\begin{abstract}
SUMARIO: I. Introducción. II. El abandono de la "Cláusula Calvo"y un ius standi unidireccional de facto. III. El deber de transparencia. IV. Monto de las demandas. V. Jurisdicción del Centro, base normativa aplicable y consentimiento al arbitraje. VI. La norma aplicable y el criterio del antecedente vinculante (stare decisis). VII. Garantías de imparcialidad e independencia. VIII. Nuevas reglas, nuevas cláusulas. IX. Conclusiones. X. Bibliografía.
\end{abstract}

* Doctor en derecho (UBA, 2013); abogado (UBA, 2001) especializado en derecho internacional público. Investigador UBACyT; investigador de la Universidad Argentina de la Empresa (UADE); ex vicepresidente de la Comisión de Auditoría Integral de Tratados de Inversión y del Sistema de Arbitraje (CAITISA) de la República de Ecuador, y ex editor en español de la revista Investment Treaty News del International Institute for Sustainable Developement (IISD), Canadá (http://www.iisd.org/topic/investment). E-mail: jechande@hotmail.com.

El autor agradece el intercambio y los aportes realizados por los magistrados Guillermo Moro (Argentina), Cecilia Olivet (Uruguay/Holanda), Alberto Arroyo (México) y la doctora Luciana Ghiotto (Argentina), y los deslinda de cualquier opinión que pudiera expresarse en el presente texto. 
RESUMEN: La región sudamericana es la más afectada en el mundo en materia de demandas arbitrales referentes a inversiones privadas. El foro más acudido en la materia es el CIADI, dependiente del Banco Mundial, sin embargo, no es el único. En nuestra región, se ha venido avanzando en negociaciones sobre un mecanismo de solución de controversias dentro de la Unasur. El siguiente es un trabajo centrado en algunos aspectos problemáticos del régimen de protección de inversiones y del sistema de arbitraje y su comparación con proyectos para la creación de un Centro de Solución de Controversias en Materia de Inversiones de la Unasur, actualmente en negociación.

Palabras clave: CIADI, inversiones, Unasur, TBI.

ABSTRACT: The South American region is the most affected area in the world in terms of arbitration claims relating to private investments. Attended the forum on the subject is the ICSID of the World Bank, however is not the only one. In our region, the negotiations on a dispute settlement mechanism within the UNASUR, had been developed. The following is a work focused on some problematic aspects of the protection of investment and the arbitration system, with its comparison with projects for the creation of a Centre for Dispute Settlement on Investment of UNASUR currently under negotiation.

Key words: ICSID, investments, Unasur, BIT.

RÉSUMÉ: La région de l'Amérique du Sud est la région plus affectée au monde en termes de demandes d'arbitrage relatives aux investissements privés. Le Forum plus demandé pour cettes investissements est le CIRDI de la Banque Mondiale, mais il n'est pas l'unique. C'est en cette région, qu'on a de progrès sur les négociations pour la recherche d'un mécanisme de solution des différends au sein de l' UNASUR. Cet article se propose d'analyser quelques aspects problématiques de la protection de l'investissement et du système d'arbitrage et sa comparaison avec des projets pour la création d'un Centre de règlement des différends sur l'investissement de l'UNASUR en cours de négociation.

Mots-clés: CIRDI, investissements, UNASUR, TBI. 
Esta revista forma parte del acervo de la Biblioteca Jurídica Virtual del Instituto de Investigaciones Jurídicas de la UNAM

\section{INTRODUCCIÓN}

La región sudamericana es la más afectada en el mundo en materia de demandas arbitrales referentes a inversiones privadas. El foro más acudido en la materia es el Centro Internacional de Arreglo de Diferencias relativas a Inversiones (CIADI), dependiente del Banco Mundial y con sede en Washington. Sin embargo, no es el único foro a donde las empresas multinacionales pueden recurrir para emplazar demandas contra los Estados en donde ellas invirtieron. El régimen de protección de inversiones extranjeras constituido por Tratados Bilaterales de Inversión (TBI) y por las reglas, casos y tribunales constituidos en el CIADI y otros foros, se encuentra actualmente en el centro de un fuerte debate a nivel internacional, tanto en el ámbito académico internacional, ${ }^{1}$ como también — y como era de esperarse- entre los Estados más afectados.

Así es como se han realizado ya dos Conferencias Ministeriales de Países Afectados por Intereses Transnacionales (la primera realizada en Guayaquil, Ecuador, el 22 de abril de 2013, ${ }^{2}$ y la segunda en Caracas, Venezuela, el 10 de septiembre de 2014) ${ }^{3}$ que han convocado a más de treinta países de América Latina, Asia y África, para tratar problemas que este régimen ha presentado para esos países. A nivel regional, el debate se ha puesto en marcha en la búsqueda de mecanismos de solución de disputas alternativos a los foros habituales. Paralelamente en nuestra región, se ha venido avanzando en negociaciones sobre un mecanismo de solución de controversias dentro de la Unión Suramericana de Naciones (Unasur).

El siguiente es un trabajo que compara el proyecto de creación de un Centro de Solución de Controversias en materia de Inversiones de la Una-

1 Entre muchas otras publicaciones podemos mencionar como reflejo de los debates académicos a nivel global: "Declaración Pública sobre el Régimen de Inversión Internacional”, disponible en: http://www.osgoode.yorku.ca/wp-content/uploads/2014/11/Declaraci\%C3\%B3n-P $\%$ C3\%BAbli ca.pdf.

2 "Impulsan el Observatorio del Sur sobre Inversiones y Trasnacionales", disponible en: http: //notas.org.ar/2014/09/11/observatorio-sur-transnacionales-venezuela-ecuador/.

3 "Países afectados por intereses transnacionales crearán Observatorio del Sur sobre Inversiones y Transnacionales", disponible en: http: / /www.vtv.gob.ve/articulos/2014/09/10/paisesafectados-por-intereses-transnacionales-crearan-observatorio-del-sur-sobre-inversiones-y-transnaciona les-1245.html. 
Esta revista forma parte del acervo de la Biblioteca Jurídica Virtual del Instituto de Investigaciones Jurídicas de la UNAM

sur (en adelante Centro Unasur) — actualmente negociándose y que es tomado por los discursos oficiales en la región ${ }^{4}$ como posible alternativa al Convenio de Washington de 1965, fundante del CIADI — con este último, perteneciente a la órbita del Banco Mundial. El régimen de protección de inversiones aplicado en el CIADI presenta una gran cantidad de problemas para los países en desarrollo. Muchos de ellos están dados en la forma en que las normas y derechos son interpretados por los tribunales arbitrales, pero otros tantos son dados por motivos de fondo, es decir, por cómo fue pensado y constituido el régimen y la dirección que éste ha tomado. ${ }^{5}$

Los problemas formales quizá puedan ser resueltos dentro del mismo sistema vigente mediante las reformas necesarias para superar estos inconvenientes. Pero los problemas de fondo tienen que ver con la dirección y el objetivo del sistema arbitral y del régimen de normas internacionales para la protección de las inversiones extranjeras, lo cual acepta premisas que no han sido probadas por la empiria, así como en mitos que los hechos refutan y que poseen una clara dirección en garantizar la brecha existente entre países desarrollados y en desarrollo, así como en garantizar ciertos privilegios para el capital privado transnacional.

4 "Correa pidió crear «urgente» un tribunal de arbitraje regional y revisar el funcionamiento de la UNASUR", disponible en: http://www.telam.com.ar/notas/201412/87782-correa-pidio-crear-urgente-un-tribunal-de-arbitraje-regional-y-revisar-el-funcionamiento-de-la-unasur. html; "Uruguay asume la presidencia temporal de UNASUR", http://www.notimerica.com/politica /noticia-iberoamerica-uruguay-asume-presidencia-temporal-unasur-urge-crear-centro-arbitrajeregional-20141205005506.html; "Comisión de UNASUR alista Centro de Arbitraje Regional”, disponible en: http://www.noticierolegal.com/component/content/article/35-unasur/8180comision-de-unasur-alista-centro-de-arbitraje-regional.html; "Unasur tendrá su centro de arbitraje sobre inversiones en este mismo año", disponible en: http: / / noticias.lainformacion.com / policiay-justicia/corte-o-tribunal-interna cional/unasur-tendra-su-centro-de-arbitraje-sobre-inversiones-eneste-mismo-ano_THORIEyffiOLYBX ZoN8gn6/; "La Unasur tendrá su centro de arbitraje en el 2015”, disponible en: http://www.elciudadano.gob.ec/la-unasur-tendra-su-centro-de-arbitraje-enel-2015/

5 Ziadé, N., "Is ICSID heading in the wrong direction?", Global Arbitration Review, 24 de febrero de 2015, disponible en: http://globalarbitrationreview.com/news/article/33574/is-icsidheading-wrong-direction/, en ese artículo, el ex secretario general del CIADI, Nassib Ziadé, expresa sus críticas hacia la dirección que el organismo posee y fundamenta con ello los motivos de su renuncia en 2011. Gharavi, H., "ICSID annulment committees: the elephant in the room”, Revista GAR, 24 de noviembre de 2014, disponible en: http: / /globalarbitrationreview. $\mathrm{com} /$ news/article/33193/icsid-annulment-committees-elephant-room/. Este artículo se aboca a críticas sobre los Comités de Anulación de laudos dentro del CIADI y las irregularidades que socavan la legitimidad del organismo. 
Esta revista forma parte del acervo de la Biblioteca Jurídica Virtual del Instituto de Investigaciones Jurídicas de la UNAM

\section{El abAndono DE LA “Cláusula CALVO” Y UN IUS STANDI}

UNIDIRECCIONAL DE FACTO

Uno de los primeros problemas es la ruptura de la denominada "Cláusula Calvo", que establecía que cualquier disputa que una empresa extranjera debiera mantener con el Estado huésped de su inversión, debía tramitarse dentro de la jurisdicción doméstica, es decir, ante los tribunales del Estado huésped de la inversión. Sin embargo, muchas veces esto podía implicar que, ante cualquier arbitrariedad por parte de ese Estado receptor de la inversión, la empresa extranjera viera sus derechos lesionados y que los alcances de los medios judiciales locales resultaran insuficientes o carentes de la imparcialidad necesaria como para impartir verdadera justicia. Esta situación ya tenía un remedio dentro del derecho internacional y era mediante la protección diplomática generada a partir del derecho consuetudinario.

La protección diplomática es aquella que el Estado de la nacionalidad de la persona extranjera — sea esta física o jurídica - ejerce sobre el Estado huésped de la inversión ante un acto u omisión de éste en supuesta violación con el derecho internacional. El bien protegido en este caso son las buenas relaciones internacionales, ya que la afectación de nacionales de un Estado en el extranjero bien puede acarrear conflictos diplomáticos que las entorpezcan y, eventualmente, acareen su ruptura.

En cambio, lo que las normas actualmente sostienen en los TBI es, por ejemplo, el derecho de que el inversionista extranjero pueda demandar al Estado huésped directamente ante una instancia internacional, no sólo evadiendo la jurisdicción local, ${ }^{6}$ sino además accionando contra un sujeto de derecho internacional como si fuera otro sujeto de la misma naturaleza jurídica. Esta potestad le permite percibir directamente los montos indemnizatorios con prescindencia de la actuación de su Estado de nacionalidad, ${ }^{7}$

6 Castillo, Y., "El recurso a los derechos humanos en arbitrajes y acuerdos internacionales de inversión", Anuario Mexicano de Derecho Internacional, México, vol. XII, 2012, p. 65; Van Harten, G., Investment Treaty Arbitration and Public Law, Nueva York, Oxford University Press, 2007, pp. 50, 110.

7 Bercelona Traction Light \& Power Co., sentenciado en 1970, es un típico caso en donde la Corte Internacional de Justicia analizó la afectación de una política pública tomada por el Reino de España que impedía el envío de remesas al extranjero, medida que originó el reclamo de accionistas de la mencionada empresa para que el Estado del cual eran nacionales (Bélgica) 
Esta revista forma parte del acervo de la Biblioteca Jurídica Virtual del Instituto de Investigaciones Jurídicas de la UNAM

no obstante, una persona jurídica no es un sujeto de derecho internacional pues carece de muchas de las atribuciones y capacidad que éstos poseen, como es la de celebrar tratados que establecen las obligaciones antedichas. ${ }^{8}$

En 1965, América Latina fue la región del mundo que en bloque rechazó la idea de crear el CIADI, manteniéndose firme a la Doctrina Calvo. Fue así como el primer borrador de la Convención del CIADI, que se elaboró en 1963 y fue aprobado por la Junta de Gobernadores del Banco Mundial en su reunión anual en Tokio en 1964, recibió la reprobación de diecinueve Estados de América Latina, incluyendo a Argentina, Brasil y México, quienes votaron en contra - además de Irak y de Filipinas - en lo que se conoce como el "No de Tokio" y del cual se cumplen en la actualidad cincuenta

ejerciera protección diplomática en su favor. Dentro de los puntos considerados por la Corte estuvo la definición de la nacionalidad de una persona jurídica de acuerdo con el lugar de constitución de la misma y su diferenciación respecto de la nacionalidad de los accionistas belgas afectados por las medidas en cuestión. En tanto, la empresa había sido creada y constituida en Canadá, la nacionalidad de la misma resultaba de dicho Estado y, dado el velo empresario, se le diferenció de la nacionalidad de sus accionistas. La Corte estableció que la afectada directa por la medida era la empresa. En consecuencia, para el ejercicio de la protección diplomática solicitada, resultaba necesario el reclamo por parte del Estado de la nacionalidad de la empresa, es decir, Canadá y no Bélgica. En conclusión, la CIJ rechazó la presentación de Bélgica por protección diplomática dado que los accionistas no resultaban ser los damnificados directos de la medida por parte de España. Caso relativo a la Barcelona Traction, Light and Power Company, Limited (segunda fase), CIJ, 1970, disponible en: http://www.unizar.es/ssalinas/documents/ Prctican8.Documenton6.pdf. Echaide, J., y Arredondo, R., "La protección de los nacionales en el extranjero", en Arredondo, R., Manual de derecho internacional público, Buenos Aires, La Ley, 2012, pp. 198-201.

8 Existe un debate dentro de los propios árbitros del CIADI sobre si los TBI les han conferido "derechos" a las empresas en forma directa o sobre si son los Estados los obligados a garantizarse recíprocamente la protección de las inversiones provenientes del otro Estado contratante, y que los TBI simplemente otorgan en favor de un tercero (pacta tertis) una mera legitimación procesal de reclamo. Tal posición ha sido sostenida por árbitros como Pedro Nikken que, en sus votos separados en los laudos por Suez c. Argentina por los casos de Aguas Argentinas S.A. y Aguas Provinciales de Santa Fe S.A., párr. 19, 27 y 36, sostuvo que: "Los TBIs contienen un catálogo de obligaciones de los Estados con respecto a sus inversiones respectivas, y no una declaración de derechos de los inversionistas. Independientemente de lo que se juzgue sobre la autonomía del trato justo y equitativo con respecto al estándar mínimo, el trato justo y equitativo representa el grado de diligencia debida que los Estados Partes en el TBI se comprometieron recíprocamente a observar con respecto a las inversiones provenientes de los nacionales de uno y otro Estado" (párr. 19), disponible en: https: / / carlosesposito.files.wordpress.com/2010/08/suez-argentina-2010-opinion-separada.pdf. Pérez Aznar, F., "La solución de controversias en materia de inversiones extranjeras", en González Napolitano, S. (coord.), Lecciones de derecho internacional público, Buenos Aires, Erreius, 2015, p. 953. 
Esta revista forma parte del acervo de la Biblioteca Jurídica Virtual del Instituto de Investigaciones Jurídicas de la UNAM

años. ${ }^{9}$ Fue recién en la década de 1990 que los países de la región ingresaron al sistema ratificando el Convenio CIADI. ${ }^{10}$

La legitimación procesal activa (ius standi) en favor de los inversionistas constituye un privilegio por una doble vía. Primero, porque las empresas locales no gozan de la misma posibilidad de demandar internacionalmente a su Estado por una medida que las afecte. Segundo, porque - aun cuando las normas formalmente no lo indican de esta manera - el mecanismo actúa de manera unidireccional: habiéndose diseñado precisamente para la protección de las inversiones, tal cometido hace referencia directa a la protección del capital privado. Desde el punto de vista formal, el sistema no limita el ius standi a "ciertas" personas jurídicas, es decir, sólo a las empresas. ${ }^{11}$ Por ende, en lo formal los Estados están técnicamente habilitados para demandar a las empresas inversionistas, pero en los hechos, la legitimación para accionar se da en la dirección contraria.

Existen distintas posiciones respecto de la posibilidad de otorgarle a las empresas transnacionales el ius standi para demandar a los Estados ante foros internacionales especializados en inversiones. Parte de la doctrina es permisiva a esta situación, y en los casos más críticos se reconoce la necesidad de fijar algún tipo de limitación o de requisito previo para acceder al foro. ${ }^{12}$ Otro sector no menor de la doctrina — crítica al actual régimen

9 Broad, R., "Recordando el «No de Tokio» cincuenta años después", disponible en: http://www.alainet.org/es/active/80823.

10 Es mayoritaria la cantidad de países latinoamericanos y caribeños que ingresaron al CIADI mediante la ratificación de la Convenion de Washington de 1965 en la década de 1990 (once casos): Argentina (1994), Bahamas (1995), Bolivia (1991), Chile (1991), Colombia (1997), Costa Rica (1993), Nicaragua (1995), Panamá (1996), Perú (1993), St. Kitts y Nevis (1995), Venezuela (1993). Esos diez años concentraron una mayor cantidad de ingresos desde esta región que los 24 años previos (ocho casos: Ecuador (1986), El Salvador (1984), Guyana (1969), Honduras (1989), Jamaica (1966), Paraguay (1983), Santa Lucía (1984), Trinidad y Tobago (1967)) o en los años posteriores (cuatro casos: Guatemala (2003), Haití (2009), San Vicente y las Granadinas (2002), Uruguay (2000)), https: / icsid.worldbank.org/apps /ICSIDWEB / icsiddocs / Documents / Lista\%20de\%20Estados\%20Contratantes\%20y\%20Signatarios\%20de1\%20 Convenio-\%20Latest.pdf.

11 En la base de datos relevada por la UNCTAD, los Estados son tomados como demandados (respondent States) o como Estado de nacionalidad de la empresa reclamante (home State). La organización siquiera toma como dato relevante el número de casos en donde el Estado ha hecho reconvenciones o reclamos propios. http: / investmentpolicyhub.unctad.org/ISDS.

12 Tempone, R., Protección de inversiones extranjeras, Buenos Aires, Ciudad Argentina, 2003, pp. 123-125. 
Esta revista forma parte del acervo de la Biblioteca Jurídica Virtual del Instituto de Investigaciones Jurídicas de la UNAM

de protección de inversiones - entiende que debe reinstalarse la Doctrina Calvo y que la capacidad de accionar contra el Estado por parte de un sujeto de derecho privado interno sólo puede darse dentro de la jurisdicción doméstica. ${ }^{13}$

Quizá pueda emplearse un criterio conjunto que establezca que la aplicación de la Cláusula Calvo en los contratos internacionales bien puede resultar previa y obligatoria reservando la jurisdicción internacional como un recurso complementario. Similares criterios se aplican en materia de derechos humanos o incluso en casos de protección diplomática que requieren el agotamiento de los recursos internos como instancia previa y obligatoria para poder acudir a jurisdicciones internacionales si el reclamo no ha sido tratado en forma acabada.

Resulta claramente polémico que mecanismos internacionales de solución de controversias puedan ser garantes de nuevos privilegios de actores transnacionales por encima de las normas y regulaciones sancionadas democráticamente por los Estados, así como también resulta cuestionable que estas normas se establezcan por sobre los derechos de las comunidades y de la ciudadanía. La jurisdicción nacional favorecería el tratar las controversias con un cúmulo más rico de obligaciones a los que los Estados han decidido someterse, tanto por la legislación nacional como por las normas internacionales. Y frente a casos arbitrarios, el recurso ante jurisdicciones complementarias podría servir para garantizar seguridad jurídica tanto para los inversionistas como a las comunidades y los Estados, y en una forma mucho más equilibrada. En consecuencia, el problema no está dado en la falta de credibilidad de las jurisdicciones nacionales, sino en la transparencia de los sistemas judiciales, lo que supone reforzar la jurisdicción en vez de eludirla.

De la misma manera, el ius standi internacional debería ser bidireccional: que las empresas pudieran demandar al Estado y que éstas pudieran ser demandadas también frente a esas cortes internacionales. El actual sistema pone el foco en la responsabilidad del Estado y no en las responsabilidades mutuas (los compromisos asumidos por el Estado, así como los compromisos asumidos por los inversionistas extranjeros) en torno a un emprendimiento económico.

13 Méndez Silva, R., El régimen jurídico de las inversiones extranjeras en México, México, UNAM, 1969, p. 95; Castillo Argañarás, L., "La protección de las inversiones extranjeras y la vigencia de la Cláusula Calvo”, disponible en: http://www.ambitojuridico.com.br/site/?n_ link=revista_artigos_leitura\&artigo_id $=12565$. 
Esta revista forma parte del acervo de la Biblioteca Jurídica Virtual del Instituto de Investigaciones Jurídicas de la UNAM

Con ello, si el motivo del acceso a la jurisdicción internacional es la falta de seguridad jurídica de un sistema judicial doméstico, también podría serlo para una comunidad determinada que podría demandar a la empresa ante este mecanismo. La seguridad jurídica no es patrimonio sólo de entes transnacionales; es de toda la comunidad, lo cual incluye al Estado y a los ciudadanos. ${ }^{14}$ No sería entonces un régimen que protegería sólo a las

14 El profesor Pierre-Marie Dupuy define que, mientras en materia de derechos humanos el individuo denunciante debe esperar al agotamiento de todos los recursos internos, en el arbitraje de inversiones el inversionista tiene acceso directo al arbitraje internacional, sin que medie dicho agotamiento (Dupuy, P. M., "Unification Rather tan Fragmentation of International Law? The Case of International Investment Law and Human Rights Law", en Dupuy, P. M. et al., Human Rights in International Investment Law and Arbitration, Nueva York, Oxford University Press, 2009, p. 48). Actualmente, el sistema internacional de inversiones no contempla la posibilidad de admitir denuncias de individuos y/o comunidades damnificadas por el accionar de una inversión extranjera en el territorio. Sobre la participación por parte de terceros, los tribunales suelen ser restrictivos a admitir presentaciones bajo la figura de amicus curiae. El recientemente firmado Tratado Transpacífico (TPP, por sus siglas en inglés) admite la posibilidad de este tipo de presentaciones (artículo 9.23.3 del capítulo 9, sobre Inversión) que queda bajo consideración del tribunal luego de haber sido consultadas las partes contendientes. Sin embargo, esta figura no posee la función de llevar a cabo un reclamo, sino de asistir al tribunal para una mejor y más informada decisión. Este tipo de presentaciones por parte de damnificados individuales o de comunidades sí se encuentra admitida en el sistema internacional de protección de derechos humanos. Sin embargo, allí las denuncias son realizadas contra el Estado como responsable primario de la violación, y no una empresa o un inversionista. El caso de Aguas Argentinas S.A. puede servir como ejemplo: un contrato firmado en 1993 a 30 años por la concesión más grande del mundo en materia de distribución de agua potable en favor de un consorcio privado. El caso se presenta en 2003 ante el CIADI por un ajuste tarifario. Previo a ello, el Estado argentino ya había multado once veces a la empresa por incumplimientos contractuales por inversiones no realizadas. Luego Argentina rescinde el contrato en 2005, no sólo por las multas impagas (que ascendían a US\$ 10 millones), sino que además se hallaron altos niveles de nitratos en el agua distribuida en el sur de la zona metropolitana de la ciudad de Buenos Aires, lo que la constituía en agua no apta para el consumo humano según estándares nacionales e internacionales. Ello afectó a millones de personas. En 2006 el tribunal admitió a un grupo de ONG como amicus curiae, aunque sin posibilidad de asistir a las audiencias. En 2010, la demanda presentada por los inversionistas fue laudada favorablemente sin que los datos presentados por las organizaciones de afectados fueran considerados para tal decisión, y se dejó la indemnización sin calcular. El monto del laudo en favor de las empresas se calculó en 2015 y asciende a US\$ 405 millones, cuando su inversión original de capital fue de US\$120 millones y se endeudó a la empresa por US\$ 706.1 millones provenientes de instituciones multilaterales (Suez, et. al. c. Argentina, Laudo sobre Responsabilidad, 2010, párr. 35). La vía para demandar a la empresa por violación del derecho humano al agua no está contemplada en el sistema internacional ni regional de 
Esta revista forma parte del acervo de la Biblioteca Jurídica Virtual del Instituto de Investigaciones Jurídicas de la UNAM

inversiones, sino uno que brindaría seguridad jurídica en un sentido más abarcativo en materia de inversión.

\section{EL DEBER DE TRANSPARENCIA}

Algo generalmente poco tratado al momento de analizar el régimen de protección de inversiones mediante el sistema arbitral, es que su dinámica proviene del arbitraje comercial privado pero aplicado a organizaciones públicas dentro del derecho internacional. Sin embargo, poseen una lógica propia de instituciones privadas. Esto opaca la legitimidad democrática con la que estos organismos públicos deben contar. Esta característica esencial debe verse reflejada en aspectos como la transparencia de los procesos o la base normativa aplicable al momento de decidir sobre el fondo de los casos, sobre todo cuando son entes públicos — como los Estados - los demandados, comprometiéndose los fondos públicos provenientes de los impuestos y contribuciones aportados por toda la sociedad.

En ese sentido, las controversias no pueden permanecer bajo carácter reservado y para el conocimiento sólo de las partes en litigio. Debería aplicarse una cláusula compromisoria de transparencia pública que obligue a los Estados a publicar sus presentaciones y las resoluciones adoptadas por el tribunal en los casos en curso. Eso facilitaría el accountability de los actos públicos, no obligaría al inversionista privado a hacerlo pero sí serviría para la transparencia y seguimiento de los laudos/sentencias que se pudieran producir. ${ }^{15}$

Una de las propuestas más generalizadas en los análisis críticos al régimen actual es la de incrementar la transparencia de los procesos arbitrales. Ello implica, entre otras medidas posibles, hacer públicos todos los docu-

derechos humanos — pues no existen mecanismos internacionales que contemplen la posibilidad de denunciarla como responsable primaria-, aunque sí la denuncia contra el Estado como responsable (en un segundo grado). En definitiva, la empresa deberá ser indemnizada por el erario público pero no rendirá cuentas a los afectados por sus acciones cometidas.

15 Reiner, C. y Schreuer, C., "Human Rights and International Investment Arbitration”, en Dupuy, P. M. et al., Human Rights in International Investment Law and Arbitration, cit., pp. 94-96; Hernández Zubizarreta, J., Las empresas transnacionales frente a los derechos humanos: historia de una asimetría normativa, Bilbao, Hegoa-Universidad del País Vasco, 2009, pp. 302 y 303, 465 479, 677-681. 
mentos presentados en los casos, excepto en extremos donde se demuestre la necesidad de confidencialidad; que las audiencias sean públicas y abiertas para la participación de personas interesadas o permitir presentaciones y participación de partes interesadas no contendientes por medio de la figura de amicus curiae, como podría ocurrir con organizaciones sociales especializadas en los casos presentados u organizaciones comunitarias afectadas en los mismos.

Los Estados Unidos y Canadá ya han incorporado algunas de estas normas de transparencia en algunos de sus acuerdos de inversiones, por ejemplo: TBI Canadá-China (artículo 28); NAFTA (artículo 1137(4)). La Comisión Europea también lo ha incluido en su mandato de negociación del Tratado Transatlántico de Comercio e Inversiones entre la Unión Europea y los Estados Unidos (TTIP). ${ }^{16}$ Sin embargo, no parecen haber sido incorporadas dentro de los borradores para la creación del Centro Unasur como posible foro alternativo en materia de inversiones. Aun siendo simples reformas dentro del sistema, este tipo de medidas deberían ser consideradas.

\section{MONTO DE LAS DEMANDAS}

\section{Criterios para el establecimiento de montos}

Otro tipo de medidas que deben ser observadas es la proporción en los montos de las demandas. En el actual régimen de protección de inversiones no existe ningún tipo de impedimento para que una empresa que haya invertido mil dólares pueda demandar luego al Estado por mil millones. Simplemente no hay restricciones ni un criterio establecido para fijar montos.

$\mathrm{Al}$ respecto, un concepto polémico dentro del régimen que resulta determinante para fijar montos indemnizatorios y que árbitros defienden y critican por igual, es el de "expectativas legítimas" — no incluido en los TBI- como extensión incorporada dentro del trato justo y equitativo

16 La Comisión Europea lo ha propuesto en su mandato de negociación del Tratado Transatlántico de Comercio e Inversiones entre la Unión Europea y los Estados Unidos (TTIP). Véase Draft TTIP Text-Trade in Services, Investment and E-Commerce (2 July 2013), disponible en: http: / / eu-secretdeals.info/upload/EU-Investment-Text-TTIP-v_July2nd-2013_v1.pdf. 
Esta revista forma parte del acervo de la Biblioteca Jurídica Virtual del Instituto de Investigaciones Jurídicas de la UNAM

- que sí figura en estos tratados- - Recordemos que en el derecho internacional quienes elaboran las normas son los Estados como únicos entes soberanos, no los jueces o árbitros como puede ocurrir dentro del derecho interno, ni siquiera para cubrir una laguna jurídica para un caso concreto. Por ende, la posibilidad de que pueda surgir un concepto que no está claramente definido dentro de las obligaciones que los Estados deciden asumir en los tratados, es algo muy cuestionable. El concepto de "expectativas legítimas" no figura incorporado a las normas, sino que surge de una interpretación expansiva de los árbitros. Además, es realmente dudoso en los hechos poder establecer un monto predeterminado, sin variables condicionantes, de los réditos futuros de una inversión a un muy largo plazo. ${ }^{17}$

El segundo problema es que nada establece topes mínimos ni máximos para los reclamos. En principio, aplicar un tope a las demandas podría significar un corset a los reclamos que genuinamente puedan emplazarse. Pero el sistema vigente muestra otra versión: el caso de Ecuador es un ejemplo de ello, pues posee el 22\% de su PIB comprometido en el monto de las demandas interpuestas por inversores extranjeros, lo cual equivale a casi la mitad del presupuesto anual del Estado ecuatoriano. Una situación así jaquea la actividad política de un Estado soberano, aun cuando dichas inversiones no han significado ni la décima parte de tales montos. ${ }^{18}$ Asumir ese riesgo implicaría un traslado de los costos del riesgo empresario a la esfera del Estado, respondiendo con dinero público riesgos que garantizan beneficios privados.

17 Resulta interesante el argumento de que, para que el inversor pueda considerar "legítimas" sus expectativas, deba haber tomado debida nota de las obligaciones del Estado derivadas de las normas en materia de derechos humanos. Dupuy, P. M. et al., Human Rights in International Investment Law and Arbitration, cit., p. 54.

18 Según algunos cálculos preliminares de la Comisión de Auditoría Integral Ciudadana de los Tratados de Inversión y del Sistema de Arbitraje (CAITISA) de la República de Ecuador, el posible monto total de las demandas contra el Ecuador arriba a montos que podrían comprometer el 22\% del PIB del país, mientras que las inversiones extranjeras han generado por cada millón de dólares invertido poco más de un puesto de trabajo nuevo. Conclusiones Finales de la CAITISA, disponibles en: https://issuu.com/periodicodiagonal/docs/conclusio nes_caitisa/1 $? e=6636556 / 33004880$, y Recomendaciones de la CAITISA, disponibles en: https: / / issuu.com/periodicodiagonal / docs/recomendaciones_caitisa / 1 ?e $=6636556 / 33004953$. Para mayor información, véase www.caitisa.org. 
Esta revista forma parte del acervo de la Biblioteca Jurídica Virtual del Instituto de Investigaciones Jurídicas de la UNAM

\section{Descarte de demandas frívolas}

A partir de la entrada en vigor del Tratado de Lisboa (2009), la Unión Europea ha iniciado un proceso de revisión sobre la política de inversión a nivel comunitario. Así, el 7 de julio de 2010 la Comisión Europea aprobó la Comunicación $\operatorname{COM}(2010) 343$ "Hacia una política global europea en materia de inversión internacional", ${ }^{19}$ como también la "Propuesta de Reglamento del Parlamento Europeo y del Consejo de la UE por el que se establecen disposiciones transitorias sobre los acuerdos bilaterales de inversión entre Estados miembros y terceros países", mediante la Comunicación $\operatorname{COM}(2010) 344$, de la misma fecha. ${ }^{20}$ En este contexto, la Comisión Europea ha propuesto la inclusión de un mecanismo para que se desestimen de manera temprana las demandas frívolas. ${ }^{21}$ Para ello pueden pensarse tres mecanismos: 1) que el inversor que pierde el caso pague todos los gastos de arbitraje del Estado. No se aplica el criterio de "costas por su orden" en estas situaciones; 2) dar al Centro arbitral la posibilidad de desestimar demandas que no pasen determinados estándares; 3) incluir el pago de un bono de litigio (una "tasa de justicia", como suele denominarse) como ocurre en muchas sedes judiciales ante los tribunales domésticos. Actualmente, el inversionista demandante acciona sin adelantar ningún tipo de compromiso, caución, ningún monto que ofrezca seriedad al planteo, por lo que acaba aplicando su demanda en forma gratuita por mera prueba para lograr sus pretensiones económicas, mientras que paralelamente puede intentar los mismos fines por otros foros. Esto no ocurre si un individuo decide accionar judicialmente ante ningún tribunal doméstico.

Sin embargo, este mecanismo no está tampoco previsto dentro del borrador del Centro Unasur. En este sentido, pareciera que los debates en nuestra región en materia de solución de controversias sobre inversiones se encontrarían rezagados comparados con los que hoy se escuchan dentro de los centros de pensamiento en las regiones más beneficiadas por el régimen. Extraña entonces que los países más perjudicados se mantengan tan

19 Comunicación $\operatorname{COM}(2010) 343$, disponible en: http://register.consilium.europa.eu/pdf/ es/10/st11/st11952.es10.pdf.

20 Comunicación $\operatorname{COM}(2010) 344$, http: / / register.consilium.europa.eu/pdf/es/10/st11/st1 1953.es10.pdf

21 EC Factsheet on Investor-to-State Dispute Settlements, p. 8, http: / /trade.ec.europa.eu/ doclib/docs/2013/october/tradoc_151791.pdf 
Esta revista forma parte del acervo de la Biblioteca Jurídica Virtual del Instituto de Investigaciones Jurídicas de la UNAM

conservadores respecto de las innovaciones que se figuran en otros foros regionales y a nivel internacional.

\section{JURISDICCIÓN DEL CENTRO, BASE NORMATIVA APLICABLE Y CONSENTIMIENTO AL ARBITRAJE}

Para que la jurisdicción del CIADI, del Centro Unasur o de cualquier otro sea aplicable, debe existir una cláusula de prórroga de la jurisdicción doméstica en favor del mismo. El tema de la prórroga de la jurisdicción es algo delicado, pues la jurisdicción es uno de los atributos de la soberanía de un Estado. No resulta recomendable que la defensa de los intereses de los particulares en un tema normativo de carácter de derecho internacional dispositivo (algo que no ocurre, por ejemplo, con obligaciones erga omnes o ius cogens como es el ámbito de protección de los derechos humanos) pueda ser prorrogado en favor de tribunales extranjeros o internacionales. Existen algunas salvedades, no obstante, que pueden realizarse sobre un método para la resolución de controversias en este tipo de materias, a saber: 1) por vía negociada entre Estados (protección diplomática); 2) manteniendo la jurisdicción doméstica (Doctrina Calvo) mediante el agotamiento de los recursos internos; 3) mediante un mecanismo de solución de controversias regional (podría ser el Centro Unasur) de jurisdicción complementaria a la nacional y con carácter prioritario frente a cualquier otro foro.

También, la jurisdicción del Centro hace al alcance frente a empresas provenientes de Estados que no sean miembros de la Unasur o del Centro y a la cláusula de consentimiento que el Estado debe otorgar para que dicha jurisdicción sea aplicable. De igual manera, aquí se hacen referencias al descorrimiento del velo societario y a la eficacia del sistema. Los borradores del Acuerdo del Centro Unasur no contemplan más que la simple prórroga de jurisdicción que puede hallarse en otro tipo de organismos similares como el CIADI - o, mismo, en los TBI. Si el sistema vigente ha mostrado abusos en cuanto a la extensión de la jurisdicción o sobre la expansión de las interpretaciones, cuál es el motivo por el que podría creerse que un nuevo sistema con las mismas reglas, el mismo derecho de fondo e incluso la posibilidad de nombrar al mismo tipo de árbitros, podría resultar en una alternativa diferente simplemente porque se encuentra en la región. 
Esta revista forma parte del acervo de la Biblioteca Jurídica Virtual del Instituto de Investigaciones Jurídicas de la UNAM

Algunos casos resultan paradigmáticos en tanto presentaron hechos no sólo sobre la afectación de inversiones, sino también relaciones con los derechos humanos, daños al ambiente e incluso el pleno funcionamiento de las instituciones democráticas. En estos procedimientos hay apreciaciones muy particulares de los tribunales arbitrales en favor de una visión acotada al momento de definir la legislación aplicable o la jurisdicción del foro y de sus interpretaciones en favor de los reclamos de los inversores.

En Aguas del Tunari v. Bolivia, ${ }^{22}$ una empresa boliviana demandó a Bolivia por un contrato firmado en Bolivia, con domicilio de cumplimiento en el territorio de ese país (la concesión de agua potable y saneamiento de la ciudad de Cochabamba), pero no ante los juzgados bolivianos sino ante el CIADI. La demandante fue Aguas del Tunari S.A., persona jurídica de nacionalidad boliviana, y no sus empresas accionistas que eran extranjeras. La separación jurídica que supone el principio del velo empresario entre los miembros de una empresa y la empresa en sí misma (la persona jurídica es una persona distinta de los sujetos que la componen) fue algo completamente soslayado por el tribunal arbitral del CIADI. El caso terminó laudándose a favor de la empresa por una indemnización no fijada, pero que motivó un escándalo y una rebelión popular en toda la región de Cochabamba; por lo que acabó por negociarse en términos simbólicos: el monto final de la indemnización fue de treinta centavos de dólar estadounidense.

Chevron v. Ecuador $\left(\mathrm{I}^{23}\right.$ y $\left.\mathrm{II}^{24}\right)$ es un caso por el que la petrolera estadounidense reclama ante el CIADI contra el Estado ecuatoriano por un juicio que

22 Aguas del Tunari S.A. v. Republic of Bolivia (ICSID Case No. ARB/02/3), Decisión de jurisdicción, disponible en: http://www.italaw.com/sites/default/files/case-documents/ita00 20_0.pdf. En efecto, en este caso no fue la accionista mayoritaria en última instancia (la norteamericana Bechtel Holdings Inc. o las empresas intermediarias con nacionalidad en Islas Caimán — International Water (Aguas del Tunari) Ltd.—- en Países Bajos — tres empresas: International Water (Tunari) B.V.; Internacional Water Holdings B.V.; y Baywater Holdings B.V.- ), en Luxemburgo (International Water (Tunari) SARL), o en Uruguay (Riverstar International S.A.), sino que fue la empresa boliviana Aguas del Tunari S.A. la titular directa del reclamo que fuera aceptado por el tribunal del CIADI. Para mayores detalles, véase los gráficos de las estructuras accionarias en párrs. 61 y 71 del laudo citado.

23 Chevron Corporation and Texaco Petroleum Company v. The Republic of Ecuador (PCA Case No. 34877), Laudo, disponible en: http://www.italaw.com/sites/default/files/case-documents / ita0154.pdf.

24 Chevron Corporation and Texaco Petroleum Company v. The Republic of Ecuador (PCA Case No. 2009-23) (II), Laudo (I), disponible en: http://www.italaw.com/sites/default/ 
Esta revista forma parte del acervo de la Biblioteca Jurídica Virtual del Instituto de Investigaciones Jurídicas de la UNAM

la empresa perdió en manos de las comunidades indígenas afectadas por derrames de petróleo en las nacientes del río Amazonas. Lo que analistas ya catalogan como un "ecocidio" y que la Corte Suprema de Ecuador sentenció con una indemnización de US\$ 9,000 millones, Chevron intenta presentarlo como una "expropiación indirecta" de sus inversiones en Ecuador. El caso está actualmente en trámite. ${ }^{25}$

Un caso similar es Burlington Resources v. Ecuador ${ }^{26}$ que afectó derechos de pueblos indígenas de la Amazonia ecuatoriana, la salud pública, la protección del medio ambiente, la gestión de recursos naturales (petróleo), contratación pública, y el orden público por conflictos violentos por la explotación de petróleo. El demandante, una gran empresa de extracción de recursos con sede en Estados Unidos, tiene intereses en varias áreas de explotación en diversas áreas territoriales de la selva tropical. Las participaciones en estas áreas fueron otorgadas por el gobierno ecuatoriano en la década de 1990, como parte de los programas de ajuste estructural impulsados por los organismos financieros internacionales. La empresa demandante no pudo llevar a cabo sus operaciones planificadas debido a la oposición local a

files/case-documents/italaw1585.pdf y Laudo (II), disponible en: http://www.italaw.com/sites / default/files/case-documents/italaw4222.pdf.

25 El caso Chevron es complejo. Se trata de tres procedimientos en tres jurisdicciones distintas presentando los mismos hechos. El primero es el juicio iniciado por las comunidades indígenas afectadas por la contaminación de una de las nacientes del río Amazonas en Ecuador (Aguinda Salazar, María y otros c/ Chevron Corporation s/ medidas Precautorias), el cual tuvo sentencia condenatoria por US\$ 9.511 millones a la empresa, fue apelado, la Cámara duplicó el monto de la sentencia original, y luego ésta fue revertida por la Corte Suprema ecuatoriana, dejando firme la condena inicial (http://www.lanacion.com.ar/1637798-millonario-fallocontra-chevron-en-ecuador-debera-pagar-us-9511-millones). El segundo caso es el planteado por la empresa Chevron Corp. contra Ecuador dentro de la jurisdicción norteamericana demandando al grupo de abogados denunciante Patton Boggs alegando corrupción, acciones fraudulentas y extorsión. La Cámara de los Estados Unidos falló favorablemente a la empresa, sin embargo, la firma de abogados arribó a un acuerdo con Chevron por US\$ 15 millones a cambio de que ésta retire la demanda y con un pedido de disculpas público (disponible en: http://www.eluniverso.com/noticias/2014/05/07/nota/2931566/chevron-resuelve-disputasobre-ecuador-firma-legal-patton-boggs-15). Por último, está el caso de Chevron Corp. contra Ecuador ante la Corte Permanente de Arbitraje (CPA) por el reclamo de protección de inversiones, referido en la cita anterior.

26 Burlington Resources Inc. v. Republic of Ecuador, ICSID Case No. ARB/08/5 (formerly Burlington Resources Inc. and others v. Republic of Ecuador and Empresa Estatal Petróleos del Ecuador (PetroEcuador)), Laudo, disponible en: http: / / www.italaw.com/sites/default/files/case-do cuments/italaw1094_0.pdf. 
Esta revista forma parte del acervo de la Biblioteca Jurídica Virtual del Instituto de Investigaciones Jurídicas de la UNAM

sus actividades de expropiación y de exploración. Inició su demanda contra Ecuador alegando un incumplimiento por parte del gobierno para proteger sus operaciones de la oposición indígena local. La demandante también se opuso a las medidas del gobierno para aumentar los niveles de participación pública bajo contratos de producción compartida. En una decisión inicial sobre su jurisdicción, el tribunal redujo su autoridad a las reclamaciones de expropiación bajo el TBI EE.UU.-Ecuador. El tribunal se declaró incompetente sobre presuntas violaciones de las normas de trato justo y equitativo y plena protección y seguridad, sobre la base que la demandante no aportó la suficiente antelación de estas afirmaciones. El trámite de nulidad del laudo está pronto a resolverse.

El Caso Burlington también es importante desde el punto de vista de los árbitros involucrados, pues no se trata de un tribunal arbitral cualquiera: los tres miembros resultan ser del grupo selecto de quince árbitros sobre los centenares de juristas de todo el sistema de arbitraje sobre inversiones y que han acabado resolviendo más del 50\% de las demandas. Ellos son: Gabrielle Kaufmann-Kohler (Suiza, presidente), Francisco Orrego-Vicuña (Chile, nombrado de oficio por el inversor), y Brigitte Stern (Francia, nombrada por el Estado). Esta cuestión toma en cuenta lo concentrado que se encuentra el arbitraje internacional de inversiones que, a pesar de que los árbitros provienen de listados con un sinnúmero de nombres, más de la mitad de los casos discutidos acaban siendo decididos por un grupo de tan solo quince personas que en casi todos los casos poseen un punto de vista pro-inversor. ${ }^{27}$

Aguas Argentinas y otros v. Argentina ${ }^{28}$ fue un caso en donde el consorcio empresario liderado por la francesa Suez demandó ante el CIADI por la recisión del contrato de concesión de agua potable y saneamiento más grande del mundo, luego de que el gobierno argentino la multara once veces por valores de casi US\$10 millones por incumplimientos en los compromisos

27 Eberhardt, P. y Olivet, C., Cuando la injusticia es negocio. Cómo las firmas de abogados, árbitros y financiadores alimentan el auge del arbitraje de inversiones, Bruselas y Amsterdam, CEO \& TNI, 2012.

28 Suez, Sociedad General de Aguas de Barcelona, S.A. and Vivendi Universal, S.A. (formerly Aguas Argentinas, S.A., Suez, Sociedad General de Aguas de Barcelona, S.A. andVivendi Universal, S.A.) v.Argentine Republic (ICSID Case No. ARB/03/19), Decisión de Responsabilidad, disponible en: http: //www.italaw.com/sites/default/files/case-documents/ita0826.pdf, Laudo, disponible en: http: / / www.italaw.com/sites/default/files/case-documents/italaw6304.pdf. 
Esta revista forma parte del acervo de la Biblioteca Jurídica Virtual del Instituto de Investigaciones Jurídicas de la UNAM

de inversión establecidos en el contrato y tras haberse establecido judicialmente la responsabilidad de la empresa por distribuir agua en al menos siete distritos — casi todas de la zona sur del Gran Buenos Aires — con niveles de nitratos que triplicaban los valores máximos tolerables para el organismo humano. Aun con los procesos judiciales perdidos, las multas aplicadas y, consecuentemente, la concesión rescindida en 2006, en abril de 2015 se condenó a la Argentina a pagar US\$ 405 millones.

Fedax v.Venezuela ${ }^{29}$ es un caso por el cual el tribunal del CIADI reconoció como inversionista extranjero al tenedor de un cheque, un tema de evidente naturaleza comercial doméstica.

El caso Vattenfall v. Alemania (I) ${ }^{30}$ sobre energía (carbón), gestión de recursos (agua, ríos), protección del medio ambiente (conservación de la vida silvestre), y legislación local (aprobaciones ambientales y elecciones municipales), afecta a un país desarrollado. La empresa sueca de energía Vattenfall planeaba construir y operar una planta de energía a carbón en Hamburgo. La planta produciría electricidad y calefacción. Los habitantes de la ciudad se opusieron al establecimiento de la planta haciendo hincapié en su impacto sobre el cambio climático y sobre el río Elba. Según la empresa, esta oposición contribuyó a las demoras en la emisión de los permisos requeridos para el control de las emisiones y el uso del agua, así como de la eventual denegación de un permiso de uso de agua para la producción de la planta. El proceso de aprobación se llevó a cabo junto con las elecciones locales en las que la planta fue un tema importante de la campaña electoral, donde ganó el Partido Verde alemán, quien tomó las demandas sociales y transformó al rechazo de la instalación de la planta en una posición de gobierno en Hamburgo. Después de un litigio en los tribunales nacionales, los permisos fueron emitidos a Vattenfall con restricciones. Vattenfall presentó, entonces, un aviso de intención de llevar el tema a arbitraje bajo la Carta de Energía Europea en busca de US\$ 1.9 mil millones en concepto de indemnización. El caso plantea preguntas sobre el impacto de arbitraje

29 FEDAX N.V.v.The Republic of Venezuela (ICSID Case No. ARB/96/3), Decisión sobre jurisdicción, disponible en: http://www.italaw.com/sites/default/files/case-documents/ita0315_0.pdf, Laudo, disponible en: http://www.italaw.com/sites/default/files/case-documents/ita0316_0.pdf.

30 Vattenfall AB, Vattenfall Europe AG, Vattenfall Europe Generation AG v. Federal Republic of Germany (ICSID Case No. ARB/09/6) (I), Laudo, disponible en: http://www.italaw.com/sites/ default/files/case-documents/ita0890.pdf. 
Esta revista forma parte del acervo de la Biblioteca Jurídica Virtual del Instituto de Investigaciones Jurídicas de la UNAM

de inversión en la capacidad de los gobiernos para adoptar o modificar las medidas ambientales, en especial después de las elecciones.

Recientemente, en mayo de 2012, la misma empresa volvió a demandar a Alemania por al menos US\$1,000 millones. Este nuevo caso (Vattenfall c/ Alemania (II)31) tiene como eje principal el atacar una medida de política pública tomada por Alemania de revertir su plan de energía nuclear tras el desastre de Fukushima, Japón, en 2011. Dicho accidente motivó a que el gobierno alemán reconsiderara la decisión de mantener su plan de energía nuclear. Ante amplios reclamos de la sociedad alemana, finalmente decidió ir hacia atrás y revertir una decisión tomada en 2010 de extender la cantidad de años de los permisos de funcionamiento de las plantas vigentes. La transnacional sueca Vattenfall nuevamente se sintió afectada por la decisión pública de iniciar un cambio hacia un régimen alternativo, más puro y seguro de fuentes de energía, y presentó su segunda demanda contra el Estado alemán.

Casos en donde se atentan contra las políticas antidiscriminación como las fijadas por el apartheid se dan en Foresti v. Sudáfrica ${ }^{32}$ utilizando el TBI Italia-Sudáfrica. Se trata de un grupo de inversores que demandó a Sudáfrica debido al impacto de su legislación Empoderamiento Económico Negro sobre sus activos. La legislación destinada a combatir la discriminación racial del pasado que surge del Apartheid en Sudáfrica. Requería a empresas mineras a desprenderse de una parte de sus activos con el fin de aumentar la propiedad indígena. Finalmente, el caso se resolvió en términos que eran favorables a los reclamantes. Sudáfrica acordó reducir sustancialmente la participación en la propiedad que se requiere para la desinversión por los reclamantes. Este caso indica que una demanda basada en un TBI puede afectar la aplicación de medidas de derechos humanos y plantea la posibilidad de que los gobiernos se verán disuadidos de la adopción de tales medidas, debido al riesgo de reclamaciones de los inversores.

Un caso similar presenta Postova Banka v. Grecia. ${ }^{33}$ En pleno colapso económico griego, el banco eslovaco y su accionista chipriota, Istrokapital, de-

31 Vattenfall $A B$ and others v. Federal Republic of Germany (ICSID Case No. ARB/12/12) (II), Laudo no disponible en Internet.

32 Piero Foresti, Laura de Carli and others v. Republic of South Africa (ICSID Case No. ARB(AF)/07/1), Laudo http://www.italaw.com/sites/default/files/case-documents/ita0337.pdf.

33 Poštová banka, a.s. and Istrokapital SE v. Hellenic Republic (ICSID Case No. ARB/13/8), Laudo http: / / www.italaw.com/sites/default/files/case-documents/italaw4238.pdf. 
Esta revista forma parte del acervo de la Biblioteca Jurídica Virtual del Instituto de Investigaciones Jurídicas de la UNAM www.juridicas.unam.mx

mandaron a Grecia en 2013 utilizando los TBI Eslovaquia-Grecia y GreciaChipre luego de que Grecia cambiara sus condiciones de seguro sobre sus bonos de deuda soberana dentro del estado de necesidad y ante el cambio de circunstancias que despertó la conocida bancarrota del país en 2008. En 2010, la agencia de calificación de riesgos Standard \& Poor's bajó la calificación de los bonos de deuda griegos al último estrato dado que su situación económica crítica lo llevaría a una obligada reestructuración para no caer en default. Ese mismo año Postova vendió sus bonos de deuda griega. En 2013 emplazó su demanda reclamando por la diferencia causada por la recalificación dada por las agencias a los bonos griegos considerando que dicha recalificación le había hecho perder el 53.5\% de su valor. Lo insólito es que responsabilizó a Grecia por dicha pérdida y no a las calificadoras de riesgo. Casos como los de Argentina o Grecia muestran cómo los tenedores de bonos pueden afectar las reestructuraciones de deudas soberanas, a lo que debe sumarse las conocidas demandas contra nuestro país ante jurisdicciones locales como las de Estados Unidos (el mentado litigio de los "fondos buitres”) y que comprometen seriamente la capacidad de pago de los países.

El Caso Philip Morris v. Uruguay ${ }^{34}$ está haciendo tomar conciencia al Estado uruguayo sobre el régimen de protección de inversiones, incluso si éste resulta ser la primera demanda contra Uruguay dentro del CIADI. En 2010 el gobierno decidió incrementar su política de protección a la salud siguiendo la implementación del Acuerdo Anti-Tabaco de la OMS mediante la sanción de una ley antitabaco de avanzada a nivel mundial. La nueva legislación aumenta el porcentaje cubierto en las marquillas de cigarrillos por fotografías de efectos del alto consumo de tabaco y también restringe a las empresas tabacaleras a dedicarse a la venta de un solo producto por marca. La transnacional suiza Philip Morris argumentó que dichas políticas significaban una "expropiación indirecta" de sus eventuales ganancias a futuro, y utilizó el TBI Suiza-Uruguay para plantear una demanda ante el CIADI, aun cuando el Acuerdo Antitabaco de la OMS prevé un mecanismo especial de solución de controversias para esos casos. Este único caso hizo ver al gobierno uruguayo la capacidad institucional que las empresas pueden tener de revertir políticas públicas legítimas mediante los mecanismos de demandas arbitrales dentro del CIADI y otros foros.

34 Philip Morris Brand Sàrl (Switzerland), Philip Morris Products S.A. (Switzerland) and Abal Hermanos S.A. (Uruguay) v. Oriental Republic of Uruguay (ICSID Case No. ARB/10/7), Laudo, disponible en: http: / / www.italaw.com/sites/default/files/case-documents/italaw7417.pdf. 
Esta revista forma parte del acervo de la Biblioteca Jurídica Virtual del Instituto de Investigaciones Jurídicas de la UNAM

Preocupaciones como las del Estado uruguayo no se ven reflejadas de forma suficiente dentro de las cláusulas previstas para el Centro Unasur. Tampoco se incluyen artículos que puedan activarse frente a posibles usos abusivos del mecanismo de solución de disputas. Está claro que los inversionistas pueden contar con mecanismos a utilizar para protestar frente a medidas que consideren ilegales y que lesionen sus intereses; pero también se evidencia una práctica cada vez más reiterada de abuso de las reglas de dichos mecanismos. Una polémica interesante cae, por ejemplo, sobre la definición de "nacional" como limitante o no de la legitimación procesal activa por parte de un inversionista privado en contra del Estado receptor donde se ha alojado dicha inversión. La propuesta de la Unasur puede contener una exclusión de nacionalidad, es decir, definir quiénes no serían considerados nacionales, algo que no se evidencia de la lectura de los borradores del Acuerdo.

Otra propuesta sería determinar explícitamente los criterios de atribución de nacionalidad en los instrumentos que cada Estado celebre prestando su consentimiento a la jurisdicción del nuevo Centro. La idea principal sería que pudieran accionar empresas extranjeras que directamente están relacionadas a la inversión y que se ven afectadas por una medida del Estado, pero no sus accionistas o entes controladores ulteriores, de modo que se tenga certeza de los derechos y la protección otorgada por los tratados internacionales y no que un accionista último minoritario, por el mero hecho de poseer una acción comprada en bolsa de una controlante en tercera instancia pueda demandar al Estado huésped de la inversión como si hubiera adelantado capital en forma directa en el territorio donde actúa la filial. También debería incorporarse alguna limitación para evitar casos como el de Aguas de Tunari v. Bolivia, en donde una empresa boliviana pudo demandar a su Estado ante el CIADI eludiendo la jurisdicción local.

Otra reforma necesaria dentro del régimen actual es el retiro del consentimiento al arbitraje. El Convenio CIADI contempla esta posibilidad en una forma específica y siempre que el Estado expresamente haya presentado una solicitud de exclusión sobre temas o áreas específicos. Un ejemplo a citar es el de Ecuador que, enmarcado en lo dispuesto por el artículo 25(4) del Convenio CIADI, retiró su consentimiento a ser objeto de demandas que se relacionaran con recursos naturales dos años antes de retirarse definitivamente del organismo. ${ }^{35}$

35 El gobierno ecuatoriano, en diciembre de 2007, notificó al CIADI que de conformidad con el artículo 25(4) del Convenio del CIADI “no consentirá en someter a [su] jurisdicción 
Esta revista forma parte del acervo de la Biblioteca Jurídica Virtual del Instituto de Investigaciones Jurídicas de la UNAM

Otra forma de retiro del consentimiento más amplia es el retiro directo del CIADI mediante la denuncia de su convenio constitutivo. El retiro del Estado del CIADI no obsta que mantenga su membresía dentro del Banco Mundial, pero deja de obligarle respecto de demandas sobre inversión. El Estado pasaría a ser un Estado no miembro del CIADI y solamente podría ser objeto de demandas ante el Mecanismo Complementario de dicho organismo, cuya jurisdicción eventualmente debería ser aceptada caso por caso.

Una posible estrategia para que un futuro Centro del Unasur pase a ser la opción preeminente - luego del agotamiento de los recursos localesdel arbitraje en la materia podría ser que los países miembros del Unasur desaforen estas cuestiones de los organismos cuestionados.

\section{LA NORMA APLICABLE Y EL CRITERIO DEL ANTECEDENTE VINCULANTE} (STARE DECISIS)

El borrador del Acuerdo para el Establecimiento del Centro Unasur posee una abierta intención de instalar a este nuevo foro regional dentro de las opciones en materia de solución de controversias sobre inversiones. Dentro de la temática de las inversiones extranjeras puede encontrarse una diversidad de foros para la resolución de conflictos: el CIADI, ${ }^{36}$ la Cámara de Comer-

las diferencias que surjan en materias relativas al tratamiento de una inversión, que se deriven de actividades económicas relativas al aprovechamiento de recursos naturales como petróleo, gas, minerales u otros". Notificación de Ecuador al CIADI del 4 de diciembre de 2007, disponible en: http://icsid.worldbank.org/ICSID/ICSID/ViewNewsReleases.jsp. Adicionalmente indicó que: "Todo instrumento contentivo de la voluntad previamente expresada por la República del Ecuador en someter esta clase de diferencias a la jurisdicción del Centro, que no se haya perfeccionado mediante el expreso y explícito consentimiento de la otra parte previa la fecha de presentación de esta notificación, es retirado por la República del Ecuador, con eficacia inmediata a partir de esta fecha”. Sobre los efectos de esta notificación, véase a Montañés, Marco Tulio y Andrade Cadena, Xavier: "Introductory Note to Ecuador>s Notice under ICSID Article 25(4)”, International Legal Materials, Washington D.C., vol. 47, 2008, pp. 154-161, citado en: http: / / www.latinarbitrationlaw.com/renuncia-al-arbitraje-previsto-en-untratado-el-caso-ecuatoriano/.

36 https://icsid.worldbank.org/apps/ICSIDWEB/Pages/default.aspx (sitio web oficial). 
Esta revista forma parte del acervo de la Biblioteca Jurídica Virtual del Instituto de Investigaciones Jurídicas de la UNAM

cio de Estocolmo (CCE), ${ }^{37}$ la Corte Permanente de Arbitraje (CPA) ${ }^{38}$ de La Haya, las reglas de arbitraje de la Comisión de las Naciones Unidas para el Derecho Mercantil Internacional (CNUDMI, pero más conocida por su sigla en inglés como "reglas UNCITRAL), ${ }^{39}$ son los foros más conocidos a los que se pueden sumar otros más específicos surgidos de tratados de libre comercio (TLC) como el estipulado en el Capítulo 11 del Tratado de Libre Comercio de América del Norte (o NAFTA, en inglés). Sin embargo, sobre las normas aplicables, los estándares sustantivos e incluso las reglas procesales suele aplicarse de facto el criterio del precedente judicial (stare decisis) típico del common law anglosajón, pero no de otros sistemas jurídicos - como el sistema continental que se practica en gran parte de Europa y en toda América Latina - y mucho menos del derecho internacional.

Existen razonadas críticas en cuanto a la aplicación del criterio del stare decisis anglosajón en foros que son internacionales e incluso en casos con Estados que no poseen dicho sistema jurídico. ${ }^{40}$ La pregunta que cabe es si un nuevo centro de arbitraje en la materia, esta vez dentro de la región como el que se proyecta en la Unasur, mostrará una continuidad en esta utilización de jurisprudencia producida por tribunales que no son los propios o siquiera son tribunales estables, puesto que muchos son establecidos ad hoc.

Hasta el momento, el borrador del Centro Unasur no contempla incluir una regla sobre fuentes de derecho aplicables. Una propuesta viable podría seguir los criterios dados por el artículo 38 del Estatuto de la CIJ, que también sirve doctrinariamente para establecer las fuentes numeradas del derecho internacional. Las fuentes principales del derecho internacional poseen un fuerte hincapié en la creación voluntaria de normas mediante la participación consentida de los Estados. Ello evidentemente contraría el establecimiento de normas vía interpretación o derecho pretoriano de los árbitros, con interpretaciones expansivas que van más allá de lo acordado por los Estados en los tratados.

Otra especial referencia debería hacerse respecto de las demás normas de derecho más allá de los acuerdos de inversión, como son las Constitu-

37 http://english.chamber.se/ (sitio web oficial).

38 http: / / www.pca-cpa.org/showpage.asp?pag_id=1303 (sitio web oficial).

39 http://www.uncitral.org/uncitral/es/index.html (sitio web oficial).

40 Turyn, A., "Comentarios sobre las fuentes del derecho internacional en la protección de inversiones extranjeras”, en Pinto, M. (comp.), Las fuentes del derecho internacional en la era de la globalización, Buenos Aires, Eudeba, 2009, pp. 150 y 151. 
Esta revista forma parte del acervo de la Biblioteca Jurídica Virtual del Instituto de Investigaciones Jurídicas de la UNAM

ciones nacionales, la legislación interna, los tratados de derechos humanos ratificados por el Estado o incluso los propios contratos celebrados con la empresa. Estas también son obligaciones que el Estado ha asumido, y una interpretación congruente sería saludable para otorgar mayor seguridad jurídica a todos los posibles afectados (no sólo a las empresas) y mayor integralidad que supere la actual situación de fragmentación normativa internacional.

En lo que se refiere a la creación de un sistema alternativo de solución de controversias sobre inversiones en el ámbito del Unasur, por ejemplo, se presentan dos problemas: primero, la referencia a las normas no figura dentro de ningún tratado constitutivo de un centro o tribunal arbitral, sino en los tratados sobre inversiones: los TBI. Los borradores de las actuales negociaciones del Centro Unasur hacen referencia a que dicho tratado constitutivo no afecta las obligaciones contraídas por otros instrumentos jurídicos en materia de inversiones (por ejemplo, los TBI). Ello significa un problema, pues por otro tipo de cláusulas - como en trato de la nación más favorecida - una interpretación expansiva podría ampliar las obligaciones establecidas en los viejos TBI que continuarían siendo el "combustible jurídico" del nuevo régimen regional.

Por último, debe considerar seriamente evitar la formación del criterio del precedente (stare decisis) dentro del nuevo sistema del Unasur. Ese criterio es propio del common law pero no del esquema jurídico de los países de la región - que siguen el derecho continental — ni tampoco del derecho internacional. ${ }^{41}$ Hasta el momento, la propuesta del Centro Unasur sigue contemplando un sistema de arbitraje que no difiere demasiado del existente en el CIADI en la aplicación del stare decisis. Ello debería preocupar si lo que se busca es una alternativa a dicho sistema que tanto ha perjudicado a los países de la región. Por lo tanto, los precedentes sólo serían posibles de ser utilizados en casos de tribunales permanentes y bajo la forma jurisprudencial.

${ }^{41}$ Echaide, J., "Sobre el derecho humano al agua y la fragmentación del derecho internacional: el régimen internacional de protección de inversiones vis-a-vis las obligaciones erga omnes en materia de derechos humanos”, Revista Electrónica del Instituto de Investigaciones “Ambrosio L. Gioja”, Buenos Aires, año VIII, núm. 12, disponible en: http: / / www.derecho.uba.ar/re vistagioja / articulo_esp.php?ided $=12 \& i d s e c=2$ \&art $=208$ 
Esta revista forma parte del acervo de la Biblioteca Jurídica Virtual del Instituto de Investigaciones Jurídicas de la UNAM

\section{GARANTÍAS DE IMPARCIALIDAD E INDEPENDENCIA}

\section{Un tribunal permanente y segunda instancia procesal (apelación)}

Al estudiar la dinámica del sistema de arbitraje del CIADI se evidencian múltiples conflictos de intereses, falta de independencia y un cierto sesgo privatista que presentan muchos de sus árbitros. ${ }^{42} \mathrm{~A}$ fin de sanear esta situación, es necesario pensar en un sistema que reemplace el modelo de tribunales de arbitraje ad hoc por un cuerpo de jueces nombrados por los Estados y con carácter permanente por un periodo fijo. De esta manera, se aislaría a los jueces de intereses externos. También ayudaría a que haya mayor consistencia y precisión en la interpretación de la norma y las decisiones. ${ }^{43}$

La UNCTAD ha incluido estas ideas en una batería de propuestas que presenta como posibles mejoras al sistema. ${ }^{44}$ Pero esto también es insuficiente, pues debe considerarse que mientras que las reglas aplicables sigan teniendo una lógica de otorgamiento de derechos a las inversiones y no contemplen las obligaciones asumidas por los inversionistas en el marco jurídico doméstico, o bien en los contratos firmados por ellos con las autoridades locales, el sistema mantendrá su sesgo.

Una crítica al argumento de establecer un tribunal permanente o corte siempre es la onerosidad, y es por eso que sería preferible un mecanismo arbitral más flexible. Pero no resulta cierto tampoco el argumento de que un mecanismo flexible de solución de disputas sea más rápido, efectivo y económico para las partes en litigio. El mecanismo imperante no es más rápido: tan solo el 36\% de los casos presentados ante el CIADI se resuelven por acuerdo de partes; el 64\% restante ${ }^{45}$ aguarda la decisión final de un tribunal arbitral que suele demorar entre 7 y 10 años. El mecanismo arbitral puede ser flexible pero es a la vez complejo, de larga duración, comparable con los sistemas judiciales internos de los Estados, los cuales cuentan con

42 Eberhardt, P. y Olivet, C., op. cit., 2012.

43 Van Harten, G., "A Case for International Investment Court”, Inaugural Conference of the Society for International Economic Law, 16 de julio de 2008, disponible en: http://papers.ssrn. com/sol3 / papers.cfm?abstract_id=1153424.

44 UNCTAD, World Investment Report 2013, Global value chains: investment and trade for development, p. 116, disponible en: http://unctad.org/en/PublicationsLibrary/wir2013_en.pdf.

45 CIADI, Carga de casos del CIADI - Estadísticas (2015-1), 2015. 
Esta revista forma parte del acervo de la Biblioteca Jurídica Virtual del Instituto de Investigaciones Jurídicas de la UNAM

la ventaja de poseer reglas más claras y balanceadas para el arribo a una sentencia judicial.

Tampoco se trata de un mecanismo más efectivo: en rigor de verdad, la ejecución de los laudos arbitrales en definitiva depende de su reconocimiento de sentencias dictadas en el extranjero receptadas en las legislaciones internas de los Estados demandados. ${ }^{46}$ Puede ocurrir que ello signifique un nuevo proceso ejecutivo a instancia judicial interna, con lo cual el laudo firme es comparable a un título ejecutivo que debe todavía ser presentado en sede doméstica. Por ello es que los laudos favorables suelen resolverse por presiones políticas externas al mecanismo arbitral, lo cual suma argumentos a la falta de transparencia en la aplicación del sistema.

Por último, tampoco resulta económico: la ultra-especialización en la materia y los recovecos procesales y de fondo muchas veces provocan que se incremente el gasto utilizado por los Estados en su defensa con la contratación de bufetes privados. En realidad, son pocos los Estados que dedican su defensa en arbitrajes ante este tipo de demandas en manos de las procuraciones oficiales. La contratación de bufetes privados - sea para que asesoren, auxilien o representen directamente la defensa del Estado- eleva los gastos en cientos de millones de dólares, ${ }^{47}$ lo cual no difiere de los gastos que requiere el funcionamiento de una corte y el arreglo judicial. La diferencia del segundo caso está dada nuevamente en la claridad de los criterios aplicables sobre la interpretación de normas, así como en la previsibilidad del sistema sobre la utilización de antecedentes jurisprudenciales que, a diferencia del régimen arbitral, suele ser tomada en forma menos aleatoria.

Por ende, la creación de un cuerpo estable de magistrados en un tribunal de carácter permanente no supone necesariamente gastos que resulten tan elevados en comparación con el sistema de arbitraje vigente. Posiblemente, un sistema basado en el arreglo judicial redunde en un sistema con mayor grado de transparencia y menor grado de arbitrariedad, lo cual ha de servir

46 En Argentina, los laudos dictados por organismos internacionales, tribunales arbitrales o tribunales extranjeros, para ser ejecutadas en el país, requieren de un procedimiento de reconocimiento de ejecución según los artículos 517 y ss. del Código Procesal Civil y Comercial de la Nación Argentina.

47 La auditoría que está llevando adelante la CAITISA en el Ecuador estima hasta el momento que los gastos realizados solamente en defensa frente a las demandas de inversionistas en este régimen asciende aproximadamente a los US\$ 118 millones de dólares para el Estado ecuatoriano. 
para reequilibrar objetivamente la balanza de derechos y obligaciones entre Estado e inversor extranjero.

Una corte permanente permitiría, además, estabilidad en los cargos de los magistrados, evitando el fenómeno de rotación de cargos que actualmente suelen practicar los árbitros del CIADI, que mañana serán abogados de empresas demandantes, para luego volver a ser nombrados por dichas empresas como árbitros de próximos casos. ${ }^{48}$ Sin embargo, hoy no existe ninguna limitación en la propuesta en mesa del Unasur que impida casos de "puertas giratorias” en donde un árbitro pueda ocupar simultánea o sucesivamente el rol de abogado de parte de un inversionista demandante en otro caso.

\section{Financiamiento y sistema de descalificación de árbitros}

Algunas de las reformas dentro del régimen actual pueden relacionarse con los motivos de descalificación y recusación de árbitros, los cuales son extremadamente limitados en el CIADI, así como en otros foros de arbitraje en materia de inversiones. La interpretación del grado de manifiesto de las causales de recusación depende del propio Tribunal Arbitral. En un régimen donde se reiteran casos de conflictos de intereses en sus árbitros y donde ocupan uno u otro lado del escritorio dependiendo de cada caso, es probable que los pedidos de recusación, atendidos por esos mismos árbitros, no prosperen.

Incluso para el caso de un sistema arbitral, existen códigos de conducta para árbitros y representantes de partes a nivel internacional. Los más reconocidos son los propuestos por el Colegio de Abogados Internacional (IBA, por sus siglas en inglés), ${ }^{49}$ aunque son de carácter voluntario y no son lo suficientemente estrictos. En el marco de las negociaciones del Acuerdo Transatlántico de Comercio e Inversiones (TTIP, por sus siglas en inglés) con Estados Unidos, la Unión Europea ha propuesto recientemente incluir un código vinculante para árbitros. ${ }^{50}$ Sin embargo, aún no ha presentado una propuesta más desarrollada de qué incluiría.

48 Eberhardt, P. y Olivet, C., op. cit., 2012.

49 IBA Guidelines on Conflicts of Interest in International Arbitration (2004) and on Party Representation in International Arbitration (2013), disponible en: http: / / www.ibanet.org/Publications/publications_IBA_guides_and_free_materials.aspx\#conflictsofinterest

50 Draft TTIP Text (Limited) - Trade in Services, Investment and E-Commerce (2 July 
En este sentido, sostenemos que un Tribunal Permanente sería una propuesta superadora, pero bien podría irse por una propuesta de base como la aplicación de un Código de Conducta Vinculante de árbitros del Unasur, algo que es compatible dentro del actual marco arbitral. Este Código al menos debería incluir dos requisitos básicos: (1) que los árbitros no tengan conflictos de intereses que creen una apariencia de falta de imparcialidad, y (2) que no puedan ejercer ni como consultores ni como expertos en casos de inversión durante al menos dos o tres años después de sus servicios como árbitros.

Sobre el financiamiento, la propuesta del Centro Unasur deja en claro el financiamiento de dicha institución, pero mantiene, sin embargo, el carácter remunerativo que los árbitros utilizan en el CIADI: son ellos los que determinan sus propias remuneraciones y lo hacen por caso, sin criterios preestablecidos que brinden objetividad a su determinación. Por ende, el ánimo de lucro puede animar a los árbitros en su actividad que, sumada a la falta de limitaciones en la rotación de cargos, puede fomentar una repetición de la "industria del juicio" que se da actualmente en el CIADI pero dentro del ámbito regional.

\section{NUEVAS REGLAS, NUEVAS CLÁUSULAS}

\section{Trato nacional, cláusula de la nación más favorecida y trato justo y equitativo}

No existen pruebas concluyentes de que los TBI atraigan la inversión externa. Esto hoy es sostenido desde organismos internacionales, académicos, sectores sociales, e incluso por algunos árbitros. Por ende, los TBI no son la herramienta necesaria para promover la inversión, sino que lo es el establecer un marco macroeconómico atractivo, el cual se da con elementos que van mucho más allá de las cláusulas establecidas en los TBI. Estos tratados actúan luego del fracaso de la inversión, por lo que el criterio de esperar el propio fracaso de la inversión que se adelanta no resulta un argumento convincente ni lógico.

2013) (as released by the German weekly DIE ZEIT on Febr. 27, 2014, disponible en: http: / / eu-secretdeals.info/upload/EU-Investment-Text-TTIPV_July2nd-2013_v1.pdf 
Son necesarias nuevas reglas y con ellas nuevas cláusulas para nuevos tratados sobre inversión. Los TBI poseen cláusulas que han resultado problemáticas por la interpretación expansiva y por la vaguedad con las que han sido redactadas, tales como las de "trato nacional" y el "nivel mínimo de trato" - especialmente el "trato justo y equitativo" que ha otorgado las justificaciones e interpretaciones más amplias-, que paralizan el diseño e implementación de políticas públicas responsables por parte de los gobiernos a nivel nacional pero también subnacional, local o municipal. Estas disposiciones, ambiguamente formuladas, abren la puerta a demandas inversionista-Estado por una amplia gama de medidas gubernamentales. Lo mismo ocurre con la "cláusula de la nación más favorecida" que hace radiales las obligaciones asumidas bilateralmente entre Estados (provocando el "efecto Mafezini" mediante el cual un inversionista de nacionalidad A puede reclamarle al Estado B los derechos y niveles de trato que éste acordó en un TBI con el Estado C, es decir, un Estado ajeno a su nacionalidad). Este tipo de cláusulas inhibe la posibilidad de concesiones mutuas en el ámbito de la integración regional ya que automáticamente se hacen extensivas a países extra regionales, con lo cual resultan muchas veces no en beneficios sino en impedimentos para avanzar en mayores grados de integración económica y comercial dentro de la región.

\section{Expropiación indirecta y definición de inversión}

El propio concepto de "expropiación indirecta" o "medidas equivalentes a expropiación” es polémico en su naturaleza, así como en su interpretación y aplicación. Debe, por ende, restringirse la definición de expropiación a un acto directo de un gobierno que, por causas de utilidad pública, se apropia o nacionaliza un bien tangible de un inversionista por el cual se debe de pagar una compensación justa, y el reclamo debe producirse ante la violación de alguna de estas tres condiciones. Conceptos como el indemnizar por las expectativas de ganancia "esperada o futura" cuando éstas son inciertas resulta abusivo del sistema de protección de la inversión y otorga una altísima discrecionalidad a su cuantificación.

Lo mismo resulta respecto de la definición de inversión, la cual debe restringirse a bienes o propiedades "tangibles". Existen áreas normalmente restringidas que hacen a las facultades gubernamentales o a temas estratégi- 
cos para los Estados, y muchos TBI incluyen estas áreas bajo la protección de la “inversión”. Algunos ejemplos de ello son las contrataciones públicas y las compras gubernamentales, los contratos de concesión de recursos naturales, los permisos reglamentarios, los derechos de propiedad intelectual, los instrumentos financieros (como los derivados, que han causado la explosión de la crisis financiera y económica que se vive mundialmente desde 2008), y las nociones ambiguas que predican que "asumir riesgos" es una forma de inversión. De igual manera, se consideran inversiones protegidas a las de corto plazo como bonos, inversión en bolsa de valores ("capitales golondrinas") e incluso la deuda soberana. Este tipo de "aperturas” en la definición de inversión es lo que habilita a que reclamos de naturaleza netamente comercial (que corresponderían a una jurisdicción del tipo OMC) puedan ser presentados bajo el amparo de los TBI como reclamos por inversiones.

\section{Controles de capitales y requisitos de desempeño}

Los TBI y los TLC generalmente impiden el diseño e implementación de controles de capitales y de requerimientos de desempeño, permiten o al menos toleran el flujo de capitales ilícitos y la evasión fiscal sin por ello privilegiar a las inversiones productivas por encima de las especulativas. Este es uno de los mayores riesgos que los TLC y los TBI tienen en común. Consecuentemente, el permitir la implementación de controles de capitales para prevenir y mitigar las crisis financieras resulta algo no sólo necesario sino conveniente para los Estados, sobre todo en momentos de crisis económicas y financieras internacionales como las que hoy se viven. De hecho, muchos gobiernos han utilizado estos controles en el pasado con considerable éxito para prevenirlas. Estos controles también sirven para garantizar que los capitales que entran a un país coadyuven al desarrollo económico al requerir un tiempo mínimo de permanencia en el país anfitrión. Incluso, el FMI ha reconocido la necesidad de aplicar controles de capitales y que las obligaciones bajo los TBI y TLC pueden reducir el margen de maniobra de los países para aplicar estas medidas públicas.

Además, los Estados tienen que ser capaces de exigir requisitos de desempeño a los inversionistas. La llegada de inversión externa depende más de las oportunidades de negocio que de la concesión de derechos extraordinarios. Estas exigencias no llevarán a la pérdida de competitividad para 
atraer inversión extranjera si se convierten en estándares mínimos internacionales que impidan la competencia desleal entre nuestros países.

Con estas medidas, debe a su vez crearse un espacio para privilegiar la inversión productiva y respetuosa del medio ambiente y desalentar la especulativa. Para ello, hay que implementar impuestos a las transacciones financieras e instrumentar controles a las salidas masivas de capital, previniendo así crisis e inestabilidades recurrentes. Es necesario asegurar también que las inversiones "productivas" no sean, por otro lado, destructoras del medio ambiente, como, por ejemplo, ocurre con las industrias extractivas.

\section{Cláusula de supervivencia o ultractividad}

Por último, pero no menos importante, se encuentran las denominadas "cláusulas de supervivencia" o de "ultractividad" de los TBI. Si bien la libre voluntad de las partes en un tratado es aceptable al momento de establecer las obligaciones jurídicas, cláusulas como la de ultractividad son jurídicamente poco convenientes. Los procesos de nulidad y terminación vía denuncia de los tratados estipulados en la Convención de Viena de 1969, establecen mecanismos que permiten la generación de controversias a fin de dilucidar sobre las obligaciones pendientes al momento de denunciar un tratado. Esto permite salidas negociadas diplomáticamente e incluso en arreglo judicial a fin de hallar un entendimiento. Por ende, no resulta necesaria la extensión por décadas de las obligaciones que son objeto de denuncia so pretexto de "estabilidad" para el inversor. Resulta abusivo sostener forzadamente el respeto por estas obligaciones una vez denunciadas, y suman un problema jurídico: si un tratado depende en su existencia de la voluntad en obligarse por un Estado y dicha voluntad fue retirada vía la denuncia, ¿cómo es posible que el Estado mantenga compromisos denunciados aun en contra de su voluntad? ¿Es posible que el Estado se obligue a futuro aun en los casos y cláusulas en que decide desobligarse? Igualmente, en los casos de declaración de inconstitucionalidad de estos tratados (caso de Ecuador, por ejemplo): ¿cómo es posible que un sistema jurídico se vea forzado a tolerar como vigentes cláusulas a pesar de haber sido declaradas inconstitucionales? Ello daría nacimiento a un nuevo tipo de norma jurídica: la "norma inconstitucional pero vigente", algo totalmente inaceptable bajo el buen entendimiento de cualquier sistema jurídico. 


\section{CONCLUSIONES}

Dentro de un marco general de análisis, una propuesta alternativa sobre un sistema de solución de controversias en materia de inversiones para la región debe ofrecer soluciones a los problemas planteados dentro del régimen vigente, sobre todo en el ámbito del CIADI, y que son materia de debate actualmente en distintos organismos internacionales así como en el ámbito académico especializado a nivel global.

$\mathrm{La}$ actual propuesta del Centro Unasur ofrece algunas reformas interesantes pero no significativas para constituir un sistema alternativo en lo sustancial al mecanismo planteado en el CIADI.

Las reglas y la lógica propuestas en el Centro Unasur son importadas del arbitraje comercial privado aunque de lo que se trata es de un organismo de carácter público, constituido por sujetos públicos del derecho internacional como son los Estados. En este sentido, la propuesta del Centro Unasur debe, cuando menos, considerar los debates que se están dando a nivel internacional, incluso desde y dentro de los países desarrollados, organismos internacionales o ámbitos académicos especializados. Sorprende entonces que muchas de las propuestas que giran en estos debates resulten ser todavía más osadas en los debates del FMI, la academia de los países centrales o la UNCTAD, y no en los bloques regionales de los países más perjudicados.

Hemos propuesto aquí una variedad de sugerencias que podrían perfectamente ser consideradas en el ámbito de la Unasur. El objetivo del presente trabajo no ha sido sólo aportar nuevas ideas, sino también vincular los debates académicos expertos, tanto de América Latina como de Europa y América del Norte, y buscar una sincronía con las negociaciones en curso a nivel regional. Estimamos que todavía hay una chance para incorporar muchas de estas contribuciones urgentes a fin de aprovechar la oportunidad histórica que la actual coyuntura nos ofrece a toda la región.

\section{Bibliografía}

Bohoslavsky, Juan Pablo, “¿Qué es lo que pueden hacer los países cuando actúan bajo la mirada de los TBIs?”, en Saulino, Florencia, Tratados inter- 
Esta revista forma parte del acervo de la Biblioteca Jurídica Virtual del Instituto de Investigaciones Jurídicas de la UNAM

nacionales de protección a la inversión y regulación de servicios públicos, Santiago de Chile, CEPAL, 2010, disponible en: http: / /www.cepal.org/cgi-bin/ getProd.asp?xml=/publicaciones $/ \mathrm{xml} / 1 / 42861 /$ P42861.xml\&xsl=/drni / tpl/p9f.xsl.

BoTTINI, Gabriel, "Protección a las inversiones extranjeras", en González Napolitano, Silvina (coord.), Lecciones de derecho internacional público, Buenos Aires, Erreius, 2015.

BROAD, Robin (2015). "Recordando el "No de Tokio" cincuenta años después", disponible en: http: / / www.alainet.org/es/active/ 80823.

CASTILlO ARGAÑARÁs, Luis, "La protección de las inversiones extranjeras y la vigencia de la Cláusula Calvo", Portal Ámbito Jurídico, disponible en: http: / / www.ambitojuridico.com.br/site/?n_link=revista_artigos_leitura\&ar tigo_id $=12565$.

CASTILlO, Yadira, "El recurso a los derechos humanos en arbitrajes y acuerdos internacionales de inversión”, Anuario Mexicano de Derecho Internacional, México, vol. XII, 2012.

CIADI, Carga de casos del CIADI - Estadísticas (Edición 2015-1), Washington, CIADI, Banco Mundial, 2015.

DRAFT TTIP TEXT (Limited) - Trade in Services, Investment and E-Commerce (2 July 2013) (as released by the German weekly DIE ZEIT on Febr. 27, 2014), disponible en: http://eu-secretdeals.info/upload/EU-In vestment-Text-TTIPV_July2nd-2013_v1.pdf.

DuPuY, Pierre-Marie, "Unification rather tan fragmentation of international law? The case of international investment law and human rights law", en Dupuy Pierre-Marie et al., Human Rights in International Investment Law and Arbitration, Nueva York, Oxford University Press, 2009.

Eberhardt, Pia y Olivet, Cecilia, Cuando la injusticia es negocio. Cómo las firmas de abogados, árbitros y financiadores alimentan el auge del arbitraje de inversiones, Bruselas y Amsterdam, CEO \& TNI, 2012, disponible en: http: / / www.tni.org/sites / www.tni.org/files/download/cuando_la_injusti cia_es_negocio-web.pdf y http://www.tni.org/es/briefing/cuando-la-injusti cia-es-negocio.

ECHAIDE, Javier, “CIADI y soberanía”, Revista Le Monde Diplomatique, Buenos Aires, enero de 2013.

, "Sobre el derecho humano al agua y la fragmentación del derecho internacional: el régimen internacional de protección de inversiones vis-a-vis las obligaciones erga omnes en materia de derechos humanos", 
Esta revista forma parte del acervo de la Biblioteca Jurídica Virtual del Instituto de Investigaciones Jurídicas de la UNAM

Revista Electrónica del Instituto de Investigaciones “Ambrosio L. Gioja”, Buenos Aires, año VIII, núm. 12, 2014, disponible en: http://www.derecho.uba. ar / revistagioja / articulo_esp.php?ided $=12$ \&idsec $=2$ \&art $=208$.

y ARREDONDO, Ricardo, "La protección de los nacionales en el extranjero", en ARREDONDO, Ricardo, Manual de derecho internacional público, Buenos Aires, La Ley, 2012.

FACH GÓmEZ, Katia, "Latin America and ICSID: David versus Goliath?", SSRN, 12 de noviembre de 2010, disponible en: http: / /papers.ssrn.com/ sol3/papers.cfm?abstract_id $=1708325$.

y TITI, Catharine, "El Centro de Solución de Controversias en Materia de Inversiones de Unasur: comentarios sobre el borrador de Acuerdo Constitutivo", Revista Investment Treaty News, núm. 3, t. 7, agosto de 2016, disponible en: http://www.iisd.org/sites/default/files/publications / iisd-itn-agosto-2016-espanol.pdf.

GHARAVI, Hamid, "ICSID annulment committees: the elephant in the room", Revista GAR, 24 de noviembre de 2014, disponible en: http: / / globalarbitrationreview.com / news/article/33193/icsid-annulment-committeeselephant-room/.

GRUPO DE TRABAJO SOBRE INVERSIONES DE LAS AMÉRICAS, Llamamiento a la construcción de un marco legal alternativo a los Acuerdos Internacionales de Inversión: Superando la impunidad de las Corporaciones Transnacionales a favor del interés público, 2014, disponible en: http: / / es.justinvestment.org/2014/06/ marco-legal-alternativo-a-los-acuerdos-internacionales-de-inversion/.

HERNÁNDEZ ZUBIZARRETA, Juan, Las empresas transnacionales frente a los derechos humanos: historia de una asimetría normativa, Bilbao, Hegoa-Universidad del País Vasco, 2009.

IBA Guidelines on Conflicts of Interest in International Arbitration (2004) and on Party Representation in International Arbitration (2013). Disponible en: http://www.ibanet.org/Publications/publications_IBA_guides_ and_free_materials.aspx\#conflictsofinterest.

MÉNDEZ SILVA, Ricardo, El régimen jurídico de las inversiones extranjeras en México, México, UNAM, 1969.

Morelli Rubio, Ricardo, "La protección de las inversiones extranjeras", en Arredondo, Ricardo, Manual de derecho internacional público, Buenos Aires, La Ley, 2012. 
PARKS, Ken, “Argentina Reaches \$677M Investment Dispute Settlement -Government", TheWall Street Journal, 2013, disponible en: http: / / online. wsj.com / article / BT-CO-20131018-705467.html.

PÉREZ AZNAR, Facundo, "La solución de controversias en materia de inversiones extranjeras”, en GONZÁlEZ NAPOLITANO, Silvina (coord.), Lecciones de derecho internacional público, Buenos Aires, Erreius, 2015.

REINER, Clara y SCHREUER, Christoph, "Human Rights and International Investment Arbitration”, en PIERRE-MARIE, Dupuy et al., Human Rights in International Investment Law and Arbitration, Nueva York, Oxford University Press, 2009.

Tempone, Rubén, Protección de inversiones extranjeras, Buenos Aires, Ciudad Argentina, 2003.

TURYN, Alejandro, "Comentarios sobre las fuentes del derecho internacional en la protección de inversiones extranjeras”, en PINTO, Mónica (comp.), Las fuentes del derecho internacional en la era de la globalización, Buenos Aires, Eudeba, 2009.

UNCTAD, World Investment Report 2013, Global Value Chains: Investment and Trade for Development, disponible en: http: //unctad.org/en/PublicationsLi brary/wir2013_en.pdf.

VAN HARTEN, Gus, "A Case for International Investment Court", Inaugural Conference of the Society for International Economic Law, 16 de julio de 2008, disponible en: http://papers.ssrn.com/sol3/papers.cfm?abstract_id= 1153424.

, Investment Treaty Arbitration and Public Law, Nueva York, Oxford University Press, 2007.

ZIADÉ, Nassib, "Is ICSID Heading in the Wrong Direction?", Global Arbitration Review, 24 de febrero de 2015, disponible en: http: / / globalarbitratio nre view.com/news/article/33574/is-icsid-heading-wrong-direction/. 